Review article

\title{
Understanding the Importance, Dimensions and Settings for Developing Children's Physical Activity Behaviour
}

\author{
Brendon Hyndman $\bowtie$ \\ International Graduate Centre of Education, School of Education, Charles Darwin University, Australia
}

\begin{abstract}
Promotion of regular physical activity during childhood within schools, home and community settings is important as childhood forms the foundation for physical activity habits that can track into adulthood. Despite childhood being a crucial period for developing physical activity behaviour, there is a limited understanding of the physical activity behaviours of school-aged children. The aim of this research report is to facilitate understanding of children's physical activity behaviours by outlining a range of measurement methods, behaviour models and correlates of children's physical activity. The home, community and school settings in which children engage in physical activity are also discussed. Outlining key insight into the importance, dimensions and settings of children's physical activity is vital in order to monitor and promote awareness of children's physical activity behaviour. Physical activity researchers and professionals can use the findings from this research report to consider approaches to target and evaluate children's physical activity participation in a range of contexts.
\end{abstract}

Keywords: Physical activity, children, health promotion

\section{Introduction}

The promotion of regular physical activity is a public health priority worldwide for the prevention of chronic diseases such as type 2 diabetes, obesity and cardiovascular disease (World Health Organisation, 2007). Physical activity is vital and defined as 'any bodily movement produced by skeletal muscles that results in energy expenditure' (Caspersen, Powell, \& Christenson, 1985). Promotion of regular physical activity during childhood within schools, home and community settings is important (Dobbins, De Corby, Robeson, Husson, \& Tirilis, 2009) as childhood forms the foundation for physical activity habits that can track into adulthood (Telama, 2009). Evidence suggests many children prefer engaging in sedentary activities despite physical activity options being available (Hyndman, Telford, Finch, \& Benson, 2012). Moreover, evidence suggests 31\% of children are not meeting national guidelines for moderate- vigorous physical activity (MVPA) and 67\% of children are exceeding recommendations for electronic screen time (Australian Department of Health and Ageing, 2007). Despite childhood being a crucial period for developing physical activity behaviour, we have a limited understanding of how to develop and sustain the physical activity and health of school children and adolescents (Trost \& Loprinzi, 2008; World Health Organisation, 2007).

\section{The Importance of Children's Physical Activity to Counteract Obesity}

School-aged children's obesity rates have soared to become an epidemic in recent decades (Oldridge, 2008). Recent reports indicate physical inactivity accounts for $1.5 \%$ to $3.0 \%$ of total direct healthcare costs in developed countries (Oldridge, 2008) or an estimated 1.9 million deaths worldwide (Hayman et al., 2007). Childhood obesity has been linked with metabolic syndrome, cardiovascular disease (Saland, 2007), premature mortality, psychological illness, joint and respiratory problems (Reilly, 2007). Energy consumption has been suggested to have increased among Australian children (aged 10 to 15 years) by 10 per cent between 1985 and 1995 emphasising the importance of concurrently increasing children's energy expenditure via regular physical activity (Cook, Rutishauser, \& Seelig, 2001). The increase of children's energy consumption could be a key reason for the rate of overweight and obese children continuing to escalate (Mitchell, Catenacci, Wyatt, \& Hill, 2011).

Although energy consumption can be a key contributor of obesity, a major preventative strategy is for children to participate in regular physical activity (Anderson \& Butcher, 2006). Numerous studies have identified the positive relationship between regular physical activity and the reduction of body mass index (BMI) and waist circumference associated with obese children (Jakicic \& Davis, 2011; Klein-Platat et al., 2005; Lambourne \& Donnelly, 2011). To counteract the growing obesity epidemic (Mitchell et al., 2011), research conducted in the United States (US), Europe and Australia has recognised that regular physical activity can have a positive effect in reducing the effects of obesity susceptible genes in children and adolescents (Mclennan, 2004; Osorio, 2012). Research highlights that children's motivation to be active should be targeted during early childhood, as physical activity can decline significantly by year four in primary 
schools (Trost et al., 2002). Moreover, a number of physical activity tracking studies have established children's physical activity habits can track into adulthood (Telama, 2009). Physical activity habits that have been established by year six in primary schools have been shown to track consistently into adulthood (Lindquist, Reynolds, \& Goran, 1999). It is important to target children's physical activity during primary school as once children reach adolescence physical activity behaviour is difficult to modify. It is likely that a lack of physical activity during childhood contributes to the development of obesity, which in turn results in reduced levels of physical activity, thus increasing the associated morbidity and mortality.

\section{The Importance of Children's Physical Activity to Counteract Type 2 Diabetes}

Evidence also suggests physical activity is beneficial in reducing the risk of type 2 diabetes among youth. A six year longitudinal study examining the relationship between physical activity and insulin resistance discovered that both volume and intensity of physical activity could improve children and adolescent's insulin resistance associated with type 2 diabetes (Jago et al., 2008). Many large studies of adults have identified that the risk of type 2 diabetes can be decreased by participating in brisk walking or vigorous physical activity for five hours per week (Krishnan, Rosenberg, \& Palmer, 2009), reducing electronic screen time (Krishnan et al., 2009), increasing sports activity (Chien et al., 2009) and a number of exercise and diet intervention programs (Knowler et al., 2002; Orozco-Beltran \& Cos-Claramunt, 2008; Williamson, Vinicor, Bowman, Centers For Disease, \& Prevention Primary Prevention Working, 2004). Although evidence of such programs has been rare in children, the development of cardiopulmonary fitness and weight reduction from physical activity are suggested to be successful measures to prevent type 2 diabetes in children (Benson, Torode, \& Fiatarone Singh, 2008; Benson, Torode, \& Singh, 2006; Krebs et al., 2007). Once considered a rarity in childhood, type 2 diabetes has escalated (Arslanian, 2000), highlighting the importance of encouraging such exercise programs to decrease the risk factors associated with type 2 diabetes amongst children. Previous research suggests that preventing an age-related decline in physical activity levels could be an effective strategy to reduce insulin resistance and type 2 diabetes occurrence in youth.

\section{The Importance of Children's Physical Activity to Counteract Cardiovascular Disease}

Similar to reducing the risk of obesity and type 2 diabetes, evidence suggests physical activity can reduce the risk of cardiovascular disease (CVD), the leading cause of adult death in many countries worldwide (Blair \& Church, 2004; Hamer \& Stamatakis, 2009; Metsios et al., 2009). Although, cardiovascular disease isn't expected to impact on childhood mortality, participation in regular physical activity early in life can significantly reduce its occurrence during adulthood (World Health Organisation, 2003). Research has linked children's physical activity to the development of cardio-respiratory fitness and the reduction of poor blood lipid profiles and hypertension (Boreham, Twisk, Savage, Cran, \& Strain, 1997). Similarly, an examination of CVD risk factors has revealed that participation in physical activity and weight control interventions are required to reduce CVD events amongst children (Berenson \& Srnivasan, 2005). The studies highlight that even moderate levels of physical activity can have a positive impact on CVD and reinforce the need to establish a physically active lifestyle at an early age.

\section{The Importance of Children's Physical Activity to Develop Bone Density}

Bone mineral density also appears to be positively influenced by physical activity in childhood. Evidence suggests that childhood is a critical period in which physical activity can have a significant effect on factors related to bone strength (Kannus et al., 1995; Suominen, 1993; Virvidakis, Georgiou, Kortkotsidis, Ntalles, \& Proukakis, 199). Interventions and longitudinal studies in children support this evidence that physical activity stimulates bone mineral density (Dalsky et al., 1988; Kannus, Haapasalo, Sievanen, Oja, \& Vuori, 1994). Many reports across age groups have also uncovered that children who participate in regular physical activity have increased bone density, which prevents bone loss and osteoporosis as individuals age (Tolomio, Lalli, Travain, \& Zaccaria, 2009). Maintaining bone density also appears to reduce the risk of bone fractures, emphasising the importance of participation in regular physical activity (Gregg, Pereira, \& Caspersen, 2000). With childhood a critical window of opportunity in which bone is most responsive to exercise in order to establish strong bones later in life (Calbert, Moysi, Dorado, \& Rodriguez, 1997), it is crucial that our younger generation participate in regular physical activity. Whilst the importance of developing habitual physical activity at an early age has been recognised, key strategies to develop children's physical activity behaviour need to be established and warrant further investigation.

\section{The Importance of Children's Physical Activity to Develop Cognitive Functioning and Mental Health} Increasing physical activity levels among school-aged children enhances cognitive and academic performance (Castelli, Hillman, Buck, \& Erwin, 2007; Chaddock, Hillman, Buck, \& Cohen, 2011; Grissom, 2005; Hillman, Buck, Themanson, Pontifex, \& Castelli, 2009; Pellegrini \& Bohn, 2005; Pontifex et al., 2011). Evidence suggests physically fit children have greater capacity to process information in their working memory than unfit children (Chaddock et al., 2011; Hillman et al., 2009). Children that participate in regular physical activity have also been revealed to have greater attention spans (Hillman et al., 2009), executive control (assists planning, monitoring and retrieving information; Chaddock et al., 2011) and achievement on academic assessments (Castelli et al., 2007; Grissom, 2005). In addition to cognitive functioning, physical activity has been shown to counteract psychological distress in youth (Hamer \& Chida, 2009). This is an important finding as the rate of Australian children with mental health problems is on the 
rise (Sawyer et al., 2008). Enhancing children's physical activity participation could be a key strategy to develop children's learning capacity and relieve mental stress.

\section{International and Australian Guidelines for Children's Physical Activity and Sedentary Behaviour for Children}

In an effort to encourage young people to be active, Australian and International organisations have developed physical activity guidelines and recommendations (Australian Department of Health \& Ageing, 2005; Health Canada, 2002; United Kingdom Department of Health, 1998). Introduced in 2004, Australia's physical activity guidelines for 5-18 year olds recommend that children and adolescents should engage in a minimum of one hour of MVPA each day (up to several hours) and should not spend more than two hours per day using electronic media for entertainment (e.g. computer games, internet, television; Department of Health \& Ageing, 2005). Examples of MVPA include brisk walking, jogging, stair climbing, basketball, racquet sports, soccer, dance, swimming laps, skating, strength training, lawn mowing, strenuous housework, cross-country skiing and cycling (Dobbins et al., 2009). Based on research linking active lifestyles to a reduction in obesity, the guidelines provide children with a physical activity target and assist in categorising individuals as sufficiently active (Trost, 2005).

Prior to the Australian physical activity guidelines, the "Young and Active?" framework was released in the United Kingdom, featuring physical activity guidelines for children (United Kingdom Department of Health, 1998). The primary recommendation for United Kingdom children was to participate in an hour of daily, moderate physical activity (MPA) to encourage aerobic benefits and energy expenditure (Cale \& Harris, 2001). A secondary recommendation was to engage in two sessions of weight bearing activities per week to develop muscular strength, flexibility and bone density (Cale \& Harris, 2001). The recommendations were described as focusing on a suitable range of fitness components, realistic for children and encouraging physical activity enjoyment (Cale \& Harris, 2001). Reflecting Australian physical activity guidelines, the United Kingdom guidelines were updated in 2011 to outline that children should be engaging in one hour of MVPA each day (up to several hours). Vigorous intensity activities that strengthen muscle and bone for at least three days a week and minimising the time spent sedentary (e.g. sitting) for extended periods were also recommended for children (United Kingdom Department of Health, 2011), but unlike the Australian sedentary behaviour guidelines do not quantify the time requirement.

Similar childhood physical activity recommendations have been established in the United States and Canada (Health Canada, 2012; United States Department of Health \& Human Services, 2008). In the US and Canada, guidelines recommend children and adolescents should complete a minimum of one hour of MVPA per day that should include at least three days a week participating in vigorous, muscle strengthening and bone strengthening physical activities (Health Canada, 2012; United States Department of Health \& Human Services, 2008). The United States guidelines also outline that children should undertake a variety of age-appropriate and enjoyable physical activities (United States Department of Health \& Human Services, 2008).

\section{Current Trends in Children's Physical Activity and Sedentary Behaviour}

A major concern is that physical activity habits can track from childhood into adulthood (Cleland, Dwyer, \& Venn, 2012; Herman, Craig, Gauvin, \& Katzmarzyk, 2009; Trudeau, Laurencelle, \& Shephard, 2004). According to Friedman and colleagues, "Active, energetic children tended to become active, energetic adults, and in turn remain active" (Friedman et al., 2008). More recently, a large literature review confirmed the tracking of physical activity habits from childhood to adulthood, emphasising the need to develop physical activity behaviours early in life (Telama, 2009). A 20 year tracking study of physical activity domains also identified that childhood participation in school physical education predicted total weekly physical activity and daily steps in adulthood, leisure and transport physical activity in childhood predicted adult leisure activity and childhood sport participation positively predicted adult physical activity (Cleland et al., 2012).

Children are becoming more sedentary in many countries worldwide (Arslanian, 2000) and sedentary behaviour is reported to track from childhood through to adulthood (Telama, 2009). In response to concerns about the prevalence of sedentary behaviour in children and the implications for the development of chronic disease, large population surveys were conducted in Australia to measure the current trends in children's physical activity participation (Australian Beareau of Statistics, 2006; Booth, Okely, Denney-Wilson, Yang, \& Dobbins, 2006). Recent reports indicate physical inactivity (not meeting the physical activity guidelines) accounts for $1.5 \%$ to $3.0 \%$ of total direct healthcare costs in developed countries (Oldridge, 2008) or an estimated 1.9 million deaths worldwide (Hayman et al., 2007). Within the United Kingdom, national data revealed that $44 \%$ of children weren't meeting recommended levels of physical activity of one hour of daily MVPA, with girls' activity levels decreasing with age (United Kingdom Department of Health, 2005). It has been reported in the United States that many American children aren't sufficiently vigorously active and males are more likely to meet physical activity guidelines than females (Andersen, Crespo, Bartlett, Cheskin, \& Pratt, 1998). Similar to the findings in the United States and United Kingdom, a recent Australian population survey revealed that 37\% of children were not participating in organised sport activity outside of school and $92 \%$ of children had used a computer outside of school hours. The Australian 
sedentary behaviour guidelines state screen time should be limited to a maximum of two hours per day (Australian Beareau of Statistics, 2006). It has also been suggested that energy consumption has increased in Australian children aged 10-15 years by $10 \%$ between 1985 and 1995, highlighting the importance of increasing energy expenditure in children via regular physical activity (Cook et al., 2001).

A report from the New South Wales (NSW) Schools Physical Activity and Nutrition Survey (SPANS; Booth et al., 2006) displayed that $10-20 \%$ of children weren't meeting the Australian childhood physical activity recommendation of one hour of MVPA each day. More specifically, $40 \%$ of year 10 girls (aged 15-16 years) weren't meeting the national physical activity guidelines. The report revealed that physical activity declined from year six (11-12 years old) to year 10 (15-16 years old) and healthy weight children were only slightly more active than obese children. Similar to the proportion of NSW children not meeting national physical activity guidelines, findings from the Australian Nutrition and Physical Activity Survey (2007) concluded that 31\% of children weren't meeting the national guidelines for MVPA (Australian Department of Health and Ageing, 2007) and $67 \%$ of children aged 9-16 years in the national survey were exceeding the recommended maximum of two hours of electronic screen time. The findings are reinforced by the 2009 Victorian Population Health survey that suggested almost $40 \%$ of children aged 5-12 years weren't meeting national physical activity guidelines, a rise of $10 \%$ from the 2006 Victorian survey (Serraglio, 2007). Furthermore, of concern is the increase in the proportion of children not meeting physical activity guidelines between the 5-8 (31.3\%) and the 9-12 year old age group (47.8\%). Children are an important group to target for interventions as they form personal identities and morals, beliefs and values towards physical activity (Bissonnette \& Contento, 2006), therefore it is important children are encouraged to be active early in life. The declining trends of children's physical activity levels identified from state-wide, national and International reports should be addressed at an early age to ensure the risk of chronic diseases are prevented from tracking from youth into adulthood is reduced (Telama, 2009).

\section{Measurement of Physical Activity and Sedentary Behaviour in Children}

Valid and reliable measures are essential to monitor the adherence to physical activity guidelines (Salmon \& Okely, 2009). Many different instruments have been used to measure the physical activity behaviour of children and adolescence that can be categorised as either objective or subjective measures. Objective measures include direct observation, accelerometry, heart rate monitoring, pedometry and subjective measures consist of survey questionnaire, diary or log book. Accurate use of both subjective and objective measurement of children's physical activity is important to identify physical activity trends and prevalence, health outcomes and evaluating physical activity interventions (Dollman et al., 2009). The sporadic nature of children's physical activity ensures measurement of physical activity a challenging and complex process.

All physical activity measures have advantages and limitations associated with their use. Direct observation is an effective measure when assessing the physical activity levels of a small group in a specific setting, yet can be costly and relies on a number of trained observers (Dollman et al., 2009). There is evidence that pedometers are becoming increasingly popular in physical activity research to measure children's steps and distance. Pedometers however, provide no information on the dimensions of physical activity including; intensity or duration of physical activity, cannot be used for contact sports, used during water activities, are insensitive to nonlocomotor activities and are vulnerable to data loss (Dollman et al., 2009). In contrast, the use of accelerometers can capture specific time periods, duration and intensity of children's physical activity and can be effective to assess children's physical activity in large groups, individually and to measure the effectiveness of interventions. Limitations of the accelerometer however include the large cost of the instrument, complexity to operate and analyse data and a failure to provide data regarding type of physical activity (Dollman et al., 2009). Heart rate monitoring is effectively measured at the individual level via fixing a strap around the chest, but can be negatively affected by fitness, emotion and temperature, doesn't take into account the type of activity performed and is not recommended for use with children (Dollman et al., 2009).

Subjective measures such as surveys, log books and diaries tend to be used with larger groups, although diaries are also used to obtain data from smaller populations. When surveys are conducted with children under eight years, it is recommended that proxy-report is used, as children under eight years of age have difficulty recalling their health behaviour (Riley, 2004). The positives of subjective instruments is the reduced cost of measuring physical activity amongst larger groups and the capability to obtain data on physical activity habits and contextual information that objective measures are unable to derive (Dollman et al., 2009). As most measures have limitations, the most effective approach to assess children's physical activity is to apply a combination of methods (Telford, Salmon, Timperio, \& Crawford, 2005).

\section{Models that Explain Children's Physical Activity Behaviour}

There is no single, accepted theory, model or approach which explains children's physical activity behaviour or strategies to target this behaviour. Multiple theories, models and approaches have been applied or recommended in the international literature. The transtheoretical model integrates multiple theoretical concepts and describes the cognitive strategies to modify an individual's experiences and the environment (Prochaska \& Velicer, 1997). These strategies are to support attempts to progress through stages of change from intention to 
adoption and maintenance of physical activity (Prochaska \& Velicer, 1997). The theory of planned behaviour is similar to the trans-theoretical approach, however within the theory of planned behaviour, intention is outlined as the most significant determinant of physical activity behaviour (Sallis \& Owen, 1999). The Social Cognitive Theory (SCT) is a model describing behavior change describing the individual, behavior and environmental factors that interact to predict behavior (Bandura, 2004). The SCT outlines that an individual's perception of their ability to demonstrate a specific behavior (e.g. goals, standards, facilitators and barriers), are suggested to be a key predictor of behavior change (Bandura, 2004). Moreover, the Health Belief Model attempts to explain the thought process behind an individual's decisions to modify and maintain health behavior (Rosenstock, Strecher, \& Becker, 1988). The Health Belief Model outlines that an individual is more likely to modify health behaviour if they perceive benefits and feasibility of the behaviour change (Rosenstock et al., 1988). Additionally, Self-Determination Theory (SDT) describes a framework of motivation that considers individuals to be searching for challenges and experiences to engage with and master (Deci \& Ryan, 2012; Ryan \& Deci, 2000). The SDT considers human beings to be motivated to achieve certain objectives (e.g. intrinsic, extrinsic and atrinsic motivations; Deci \& Ryan, 2012).

Until recent times, previous research had not investigated the context and broader determinants within which health behaviour occurs, rather focusing on the individual influences on physical activity behaviour (Stevenson \& Burke, 1992; Stokols, 1996). These broader influences on health behaviour may be linked to the Social-Ecological Model of human behaviour, which emphasises a need for a 'person-environment' fit (Stokols, 1996), implying that there is an association between the intra-personal (individual) level, inter-personal (social) environment level, physical environment level and policy level influences. Many health behaviour models do not show the interactions between the environmental factors and can miss vitally important influences on children's physical activity. Knowledge of these environmental factors are important to guide physical activity interventions. Attempts to modify physical activity behaviour at a single level on its own (e.g. self-efficacy) will be resisted by other environmental factors (Salmon \& King, 2010). Many factors within the environment can conspire against changes that are applied addressing a single environmental level (Salmon \& King, 2010; Stokols, 1996). Successful behaviour modification programs must not only modify an individual's behaviour, but also the multi-level environmental context in which the behaviour is taking place (Salmon \& King, 2010; Stokols, 1996). Thus, there is an increasing need to address the world's health problems by implementing multilevel interventions applying a Social-Ecological Theoretical Model (Salmon \& King, 2010; Telford, 2010).

Interventions that simultaneously affect multiple levels and multiple settings can be expected to achieve effective and long lasting physical activity outcomes (Salmon \& King, 2010). The framework aims to present an account of the diverse range of possible intra-personal, interpersonal, physical environment and policy influences on physical activity. The many levels of the social-ecological framework ensure health behaviour change is comprehensively accounted for. Therefore, the SocialEcological Model is the most appropriate theoretical model to examine children's physical activity behaviour.

\section{Mediators of Children's Physical Activity Behaviour}

A factor that could be attributed to a lack of effective interventions targeting children is the poor understanding of the factors that mediate behaviour change (Baranowski \& Jago, 2005). Mediators are defined as, "intervening causal variables that are necessary to complete a causeeffect pathway between an intervention and physical activity” (Bauman, Sallis, Dzewaltowski, \& Owen, 2002). Measurement of the mediators (e.g. mechanisms for change) of children's physical activity behaviour has been limited (Baranowski \& Jago, 2005; Brown, Hume, \& Chinapaw, 2009; Brown, Hume, Pearson, \& Salmon, 2013). There are three types of mediators for physical activity behaviour that include cognitive mediators (e.g. self-efficacy, enjoyment, outcome expectancy, perceived benefits/barriers), behavioural mediators (e.g. goal setting, rewards) and inter-personal mediators (e.g. social and peer support; Baranowski \& Jago, 2005).

A systematic review investigated studies conducted over a 21 year period which examined mediators of behavioural change on children's physical activity the review revealed that physical activity knowledge/beliefs, self-efficacy and enjoyment or preference for physical activity were the most commonly measured mediators (Salmon, Brown, \& Hume, 2009). Despite positive changes being identified for each of these mediators, none of these studies examined whether the positive changes in the mediator influenced children's physical activity behaviour or examined the mechanisms behind the physical activity increases (Salmon, Brown, \& Hume, 2009).

More recently, the most commonly reported mediator of children's physical activity has been established as selfefficacy and this has been linked to physical activity participation within a number of studies (Dishman et al., 2004; Haerens et al., 2008; Taymoori \& Lubans, 2008). Outcome expectancy, perceived benefits and physical activity enjoyment have also been positively associated with children's physical activity (Dishman et al., 2004; Haerens et al., 2008; Taymoori \& Lubans, 2008). Despite the limited evidence, research has revealed no mediation effects of changing perceived barriers, social support and enjoyment of Physical Education on children's physical activity participation.

Emerging research is starting to emphasise the important link between the mediator of enjoyment and children's participation in physical activity (Moore, Yin, Duda, Gutin, \& Barbeau, 2009; Salmon, Ball, et al., 2005). 
Enjoyment stems from kinaesthetic experiences and the achievement of personal goals and is defined as "a positive affective response to an experience that reflects generalised feelings such as pleasure, liking, and fun (Scanlon \& Lewthwaite, 1986).” The positive association between enjoyment and behaviour change is emphasised by the Self-Determination Theory (SDT; Lawman, Wilson, Van Horn, Resnicow, \& Kitzman-Ulrich, 2011). SDT outlines that if children enjoy participating in a particular physical activity (e.g. intrinsic motivation) this increases the likelihood of children adopting and maintaining participation in physical activity. Enjoyment has been shown to mediate involvement and participation in sport (McCarthy, Jones, \& Clark-Carter, 2008) and physical activities (Dishman et al., 2005; Moore et al., 2009; Motl et al., 2001). Other studies have also recognised the link between enjoyment and correlates of physical activity including self-determination (Ntoumanis, 2002), motor skill proficiency (Okely, Booth, \& Patterson, 2001), task orientation (Boyd \& Yin, 1996), self-efficacy (Rovniak, Anderson, Winett, \& Stephens, 2002), goal setting (Rovniak et al., 2002) and perceived competence (Boyd \& Yin, 1996). The emerging research examining enjoyment suggests studies should examine this mediator when judging the success of implementing physical activity interventions targeting children. Researchers have also identified a need for further investigation of mediators of physical activity and whether mediators such as enjoyment can explain the effects of interventions (Brown, Hume, \& Chin, 2009; Kriemler et al., 2011; Salmon et al., 2009).

\section{Correlates and Determinants of Children's Physical Activity}

In order to develop appropriate physical activity interventions in children, correlates and determinants of children's physical activity need to be clearly understood. Interventions that take into account influences on physical activity participation are suggested to be most effective in modifying physical activity behaviour (Baranowski, Anderson, \& Carmack, 1998). Many studies have been conducted to identify the determinants of childhood and adolescent physical activity. A comprehensive review of 108 studies published over 28 years was conducted by Sallis and colleagues (Sallis, Prochaska, \& Taylor, 2000) which reported almost $60 \%$ of the variables evaluated possessed a significant relationship with physical activity participation. The variables that were consistently linked to childhood physical activity behaviour included time outdoors, eating nutritional food, access to facilities, exercise motivation, sex (male), low parental BMI, preferences for physical activity and past physical activity participation (Sallis et al., 2000). Additionally, exercise opportunities, sex (male), exercise motivation, past physical activity participation, family and social support, Caucasian ethnicity, community sports and exercise selfefficacy were associated with physical activity participation in adolescence (Sallis et al., 2000). The failure to perform an effective meta-analysis due to the many subjects, methods, determinants and modes of analysis was a limitation of the study. Researchers also indicated the possibility that articles could have been overlooked and that many studies failed to publish negative findings. The review had strong implications for future intervention programs aimed at children and adolescence and identified groups that should be targeted for physical activity intervention including females, older adolescence and certain ethnic groups.

More recently, understanding of the determinants of youth physical activity was further enhanced. Similar to the findings from Sallis, a review of studies $(n=60)$ published between 1999 and 2005 revealed sex (male) and exercise motivation were consistently reported to influence children's physical activity participation. In contrast to the earlier review, parental education, attitude, self-efficacy, school physical activity opportunities, family influences and social support all had a significant association with children's physical activity. Furthermore, sex (male) and Caucasian ethnicity were again positively associated with adolescent physical activity. Education level of parents and socioeconomic status has been consistently shown to be correlated with physical activity in adolescents (Van Der Horst, Paw, Twisk, \& Van Mechelen, 2007). Researchers suggested that further investigation into determinants of youth physical activity is necessary to inform the development of interventions targeting physical activity and sedentary behaviour of children and adolescents (Van Der Horst et al., 2007).

\section{Important Settings for Children's Physical Activity}

Understanding the most effective strategies to promote physical activity behaviour and the settings in which to intervene is necessary to minimise sedentary behaviour during childhood that can lead to chronic disease (Kelty, Giles-Corti, \& Zubrick, 2008). By developing an understanding of the components that are important within settings and which settings are important to develop children's physical activity may inform the development of effective intervention strategies.

\section{Children's Physical Activity in the Home Setting}

The home setting is suggested to be an influential setting for youth physical activity. Researchers conducted a systematic review of 150 studies published over 25 years to establish associations between environmental settings and children's physical activity (Ferreira et al., 2007). Although investigators revealed many strong associations between the school setting and children's physical activity behaviour, it was revealed that home support for physical activity also had a significant influence on children's physical activity participation. The home setting has been suggested as crucial for providing children with access to opportunities for physical activity beyond the school setting (Kumanyika \& Parker, 2010; Kumanyika, 2008).

It has been well established that parents have control over children's access and availability of physical activity opportunities (Crawford et al., 2010; Golan, Weizman, 
Apter, \& Fainaru, 1998) and children are more likely to participate in increased physical activity at home, when equipment is available (Spurrier, Magarey, Golley, Curnow, \& Sawyer, 2008; Timperio et al., 2008). Children with at least seven items to facilitate physical activity in the home have been revealed to be two to four times more likely to engage in high levels of physical activity (Telford et al., 2005). Outside of the school setting, the yard or garden at home has been revealed as the most frequently reported place for children to engage in physical activity (Veitch, Salmon, \& Ball, 2008). Additionally, it has been implied that children possessing a large yard are more active than those with a smaller yard size (Telford et al., 2005). Crawford and colleagues (2010) established that children are more active within the home environment with the presence of parental role models, physical activity rules and siblings. Timperio and colleagues (2008) also revealed that sibling physical activity and environmental stimuli could be key physical activity strategies in the home setting. Moreover, a study of children's perceptions of physical activity in the home environment revealed bicycles, swimming pools, trampolines and basketball rings are important for children's physical activity (Hume, Salmon, \& Ball, 2005). Although a concerning finding from the study was that less than half of the primary school aged children drew any physical activity opportunities at home and over half of the children engaged in sedentary opportunities (Hume et al., 2005).

Despite the potential for children to be active within the home setting, sedentary opportunities are abundant. Girls that have a preference for watching TV and who spend greater than 30 minutes engaged with electronic media are more likely to engage in low physical activity (Salmon, Timperio, Telford, Carver, \& Crawford, 2005). It is possible that some children may see the home setting as more of a place for sedentary opportunities in comparison to the school setting (Hume et al., 2005). Mapping methodology employed by Hume and colleagues identified that within the 72 maps of the home environment children drew at least one television and regularly drew a computer (Hume et al., 2005). In contrast, a mapping study of children's perceptions of the school environment discovered primary school children rarely drew a sedentary opportunity (Hyndman et al., 2012). As there are many physical activity opportunities available during a school day (Hyndman et al., 2012), children may view the home setting as an environment to rest and recover rather than complementing the physical activities performed during the school day. Despite the home environment providing opportunities for children to be physically active, most children spend large portions of their mornings and nights in transit to and from school (Dobbins et al., 2009). This can limit children's time to be active at home. As children spend much of their days getting ready for or attending school, the school setting could be a more conducive setting for children to be physically active within.

\section{Children's Physical Activity in Community Settings}

Researchers have identified that there are many physical activity opportunities for children within community settings. Community settings have been associated with positive physical activity participation in children living in low crime rate areas (Ferreira et al., 2007). It has been revealed that design features, personal motivation, presence of friends, play equipment and amount of movement can positively influence children's use of public open spaces for physical activity (Veitch, Bagley, Ball, \& Salmon, 2006). Studies have also reported that children would like to live in a neighbourhood with people that are physically active and have access to multiple public recreation facilities that are affordable (Mota, Ribeiro, \& Santos, 2009). Safety has also been established as a major influence on children's physical activity within the community (Veitch et al., 2006; Veitch et al., 2008), as parental concerns regarding safety can restrict children's potential to be independently active in the community setting and on the time children spend engaged in active, outdoor physical activity (Jago \& Baranowski, 2004). Parents are suggested to begin encouraging independent physical activity at the conclusion of the children's primary schooling (Jago \& Baranowski, 2004), limiting the amount of time children can be active in the community beyond school hours. Within the community, the most frequently reported places for children's physical activity are the park, playground, friend's house and relative's backyard (Veitch et al., 2008). More recent studies have revealed that being outdoors (Wheeler, Cooper, Page, \& Jago, 2010), having friends in the neighbourhood and living in a closed street could also positively influence children's community physical activity (Veitch, Salmon, \& Ball, 2010).

Although many studies have explored the influence of the home (Hume et al., 2005) and community settings (Hume et al., 2005; Ries, Voorhees, Gittelsohn, Roche, \& Astone, 2008; Veitch et al., 2008), the limited time and barriers for children to engage in the recommended physical activity within these settings highlight the school setting as being crucial for children (Davison \& Lawson, 2006; Ferreira et al., 2007).

\section{Children's Physical Activity in School Settings}

A reduction in children's physical activity opportunities (Hardman, 2008) and the growth of overweight and obese youth worldwide (Eisenmann, 2006) has placed emphasis on schools as a crucial setting to develop children's physical activity. With growing attention on schools to develop physical activity, there is a need to provide children with the essential skills to be physically active (Lee, Burgeson, Fulton, \& Spain, 2007). The school environment is suggested to be the most influential setting for children's physical activity. A systematic review of 150 studies from over 25 established strong associations between school physical activity policies and school attendance on children's physical activity (Ferreira et al., 2007). School is the setting in which almost all children spend the majority of their weekdays (above 30 hours per 
week) and an ideal environment for preventative public health interventions (Dobbins et al., 2009).

The school setting provides a number of programs and positive physical activity opportunities for children that have limited access to play areas at home and the surrounding community (Dobbins et al., 2009). Schoolbased physical activity programs may include curricular initiatives (e.g. Physical Education and Sport Education programs), co-curricular (e.g. inter-school sport and school break periods) and non-curricular initiatives (e.g. after school activity programs and active transport programs; Dobbins et al., 2009). As school aged children spend the majority of their waking hours either in transit to school or within the school setting and international standards require children to attend school well into adolescence, there is encouraging scope for the school setting to reduce chronic diseases that can track into the adult population (Dobbins et al., 2009). Targeting the school setting can promote knowledge and behaviour to develop the health behaviour of those children susceptible to disease and to maintain the habits of healthy children (Dobbins et al., 2009). Schools are learning environments, therefore the capacity to equip children with the attributes to be physically active can be readily achieved. It is the quality of facilitating school physical activity programs that need to be investigated to ensure children can develop into physically educated citizens (Lee et al., 2007). The provision of quality school physical activity experiences for children's development can be affected by many factors, these multi-level factors can be enablers or barriers to children's physical activity behaviour.

\section{Conclusion}

This research report outlines the importance of developing children's physical activity behaviour to counteract a range of diseases (e.g. obesity, type 2 diabetes, cardiovascular disease) and to enhance children's physical functioning (e.g mental health, bone mass). There are a number of measures that can be used effectively to measure specific dimensions of children's physical activity (frequency, duration, intensity and type) including: direct observation, accelerometers, pedometers and self-report instruments. However, as all measurement tools have limitations, it is important that a combination of methods are employed to measure children's physical activity. Due to the complex and multifaceted nature of children's physical activity, applying a Social-Ecological Model to explore the multiple levels of influence on children's physical activity provides a useful framework to understand children's physical activity behaviour. Although many studies have explored the influence of the home and community settings for children's physical activity, the limited time and barriers for children to engage in the recommended physical activity within these settings highlights schools as the key physical activity setting for children.

\section{References}

1. Australian Beareau of Statistics (ABS). (2006). Children's participation in cultural and leisure activities, Australia. Canberra: Australian Bureau of Statistics.

2. Active, S. A. S. (2011). Start Active, Stay Active: a report on physical activity for health from the four home countries’ Chief Medical Officers. 2011. Royaume-Uni. Disponible au www. dh. gov. uk/en/Publicationsandstatistics/Publications/Publicat ionsPolicyAndGuidance/DH_128209 [cité le 9 janvier 2012].

3. Australian Department of Health and Ageing. (2005). Australia's physical activity recommendations for children and young people: Australian Government.

4. Andersen, R. E., Crespo, C. J., Bartlett, S. J., Cheskin, L. J., \& Pratt, M. (1998). Relationship of physical activity and television watching with body weight and level of fatness among children: results from the Third National Health and Nutrition Examination Survey. The Journal of the American Medical Association, 279(12), 938-942.

5. Anderson, P. M., \& Butcher, K. F. (2006). Childhood obesity: trends and potential causes. The Future of children, 16(1), 19-45.

6. Arslanian, S. A. (2000). Type 2 diabetes mellitus in children: pathophysiology and risk factors. Journal of Peditratric Endocrinology and Metabolism, 13 Suppl 6, 1385-1394.

7. Australian Department of Health \& Ageing. (2007). Australian National Children's Nutrition and Physical Activity Survey: Australian Government.

8. Bandura, A. (2004). Health promotion by social cognitive means. Health Education \& Behavior, 31(2), 143-164.

9. Baranowski, T., Anderson, C., \& Carmack, C. (1998). Mediating variable framework in physical activity interventions: How are we doing? How might we do better? American Journal of Preventive Medicine.

10. Baranowski, T., \& Jago, R. (2005). Understanding the mechanisms of change in children's physical activity programs. Exercise \& Sport Sciences Reviews, 33(4), 163.

11. Bauman, A. E., Sallis, J. F., Dzewaltowski, D. A., \& Owen, N. (2002). Toward a better understanding of the influences on physical activity: the role of determinants, correlates, causal variables, mediators, moderators, and confounders. American Journal of Preventive Medicine, 23(2), 5-14.

12. Benson, A. C., Torode, M. E., \& Fiatarone Singh, M. A. (2008). Effects of resistance training on metabolic fitness in children and adolescents: a systematic review. Obesity Reviews, 9(1), 43-66. doi: 10.1111/j.1467-789X.2007.00388.x

13. Benson, A. C., Torode, M. E., \& Singh, M. A. (2006). Muscular strength and cardiorespiratory fitness is associated with higher insulin sensitivity in children and adolescents. International Journal of Obesity, 1(4), 222-231. 
14. Berenson, G., \& Srnivasan, S. (2005). Cardiovascular risk factors in youth with implications for aging: The Bogalusa Heart Study. Neurobiological Aging, 26(1), 303-307.

15. Bissonnette, M. M., \& Contento, I. R. (2006). Adolescents' Perspectives and Food Choice Behaviors in Terms of the Environmental Impacts of Food Production Practices: Application of a Psychosocial Model. Journal of Nutrition Education, 33(2), 72-82.

16. Blair, S. N., \& Church, T. S. (2004). The fitness, obesity, and health equation: is physical activity the common denominator? The Journal of the American Medical Association, 292(10), 1232-1234. doi: 10.1001/jama.292.10.1232

17. Booth, M., Okely, A., Denney-Wilson, E., Yang, B., \& Dobbins, T. (2006). NSW Schools Physical Activity and Nutrition Survey (SPANS) 2004: Summary Report. Sydney: NSW: Department of Health.

18. Boreham, C. A., Twisk, J., Savage, M. J., Cran, G. W., \& Strain, J. J. (1997). Physical activity, sports participation, and risk factors in adolescents. Medicine \& Science in Sport \& Exercise, 29(6), 788793.

19. Boyd, M. P., \& Yin, Z. (1996). Cognitive-affective sources of sport enjoyment in adolescent sport participants. Adolescence, 31(122), 383-395.

20. Brown, H., Hume, C., \& Chin, A. M. (2009). Validity and reliability of instruments to assess potential mediators of children's physical activity: A systematic review. Journal of Science \& Medicine in Sport, 12(5), 539-548.

21. Brown, H., Hume, C., \& ChinAPaw, M. (2009). Validity and reliability of instruments to assess potential mediators of children's physical activity: A systematic review. Journal of Science \& Medicine in Sport, 12(5), 539-548.

22. Brown, H., Hume, C., Pearson, N., \& Salmon, J. (2013). A systematic review of intervention effects on potential mediators of children's physical activity. BMC Public Health, 13(1), 165.

23. Calbert, J., Moysi, J. S., Dorado, C., \& Rodriguez, L. P. (1997). Bone Mineral Content and Density in Professional Tennis Players. Calcified Tissue International, 62(1), 491-496.

24. Cale, L., \& Harris, J. (2001). Exercise recommendations for young people: an update. Health Education, 101(3), 126-138.

25. Health Canada. (2002). Canada's physical activity guide for children. Public Health Agency of Canada. Her Majesty the Queen in Right of Canada.

26. Candian Physical Activity, and Sedentary Behaviour Guidelines. (2012).

http://www.csep.ca/CMFiles/Guidelines/CSEP_Guid elines_Handbook.pdf

27. Caspersen, C. J., Powell, K. E., \& Christenson, G. M. (1985). Physical activity, exercise, and physical fitness: definitions and distinctions for health-related research. Public Health Reports, 100(2), 126.
28. Castelli, D. M., Hillman, C. H., Buck, S. M., \& Erwin, H. E. (2007). Physical fitness and academic achievement in third-and fifth-grade students. Journal of Sport \& Exercise Psychology, 29(2), 239.

29. Chaddock, L., Hillman, C. H., Buck, S. M., \& Cohen, N. J. (2011). Aerobic fitness and executive control of relational memory in preadolescent children. Medicine \& Science in Sports \& Exercise, 43(2), 344.

30. Chien, K., Cai, T., Hsu, H., Su, T., Chang, W., Chen, M., Hu, F. B. (2009). A prediction model for type 2 diabetes risk among Chinese people. Diabetologia, 52(3), 443-450. doi: 10.1007/s00125-008-1232-4

31. United Kingdom Department of Health. Choosing activity: a physical activity action plan. (2005). London (UK): Department of Health.

32. Cleland, V., Dwyer, T., \& Venn, A. (2012). Which domains of childhood physical activity predict physical activity in adulthood? A 20-year prospective tracking study. Br J Sports Med, 46(8), 595-602. doi: 10.1136/bjsports-2011-090508

33. Cook, T., Rutishauser, I., \& Seelig, M. (2001). Comparable Data on Food and Nutrient Intake and Physical Measurements from the 1983, 1985 and 1995 National Nutrition Surveys. Canberra: Commonwealth Department of Health and Aged Care.

34. Crawford, D., Cleland, V., Timperio, A., Salmon, J., Andrianopoulos, N., Roberts, R., . . B Ball, K. (2010). The longitudinal influence of home and neighbourhood environments on children's body mass index and physical activity over 5 years: the CLAN study. International Journal of Obesity, 34(7), 1177-1187.

35. Dalsky, G. P., Stocke, K. S., Ehsani, A. A., Slatopolsky, E., Lee, W. C., \& Birge, S. J., Jr. (1988). Weight-bearing exercise training and lumbar bone mineral content in postmenopausal women. Annals of Internal Medicine, 108(6), 824-828.

36. Davison, K. K., \& Lawson, C. T. (2006). Do attributes in the physical environment influence children's physical activity? A review of the literature. International Journal of Behavioral Nutrition \& Physical Activity, 3(1), 19.

37. Deci, E. L., \& Ryan, R. M. (2012). Overview of selfdetermination theory. The Oxford Handbook of Human Motivation, 85.

38. Dishman, R. K., Motl, R. W., Saunders, R., Felton, G., Ward, D. S., Dowda, M., \& Pate, R. R. (2004). Self-efficacy partially mediates the effect of a schoolbased physical-activity intervention among adolescent girls. Preventive Medicine, 38(5), 628636.

39. Dishman, R. K., Motl, R. W., Saunders, R., Felton, G., Ward, D. S., Dowda, M., \& Pate, R. R. (2005). Enjoyment mediates effects of a school-based physical-activity intervention. Medicine \& Science in Sports \& Exercise, 37(3), 478-487.

40. Dobbins, M., De Corby, K., Robeson, P., Husson, H., \& Tirilis, D. (2009). School-based physical activity programs for promoting physical activity and fitness 
in children and adolescents aged 6-18. Cochrane Database Systematic Rev iews (1), CD007651.

41. Dollman, J., Okely, A. D., Hardy, L., Timperio, A., Salmon, J., \& Hills, A. P. (2009). A hitchhiker's guide to assessing young people's physical activity: Deciding what method to use. Journal of Science \& Medicine in Sport, 12(5), 518-525.

42. Eisenmann, J. C. (2006). Insight into the causes of the recent secular trend in pediatric obesity: Common sense does not always prevail for complex, multifactorial phenotypes. Preventive Medicine, 42(5), 329-335.

43. Ferreira, I., van der Horst, K., Wendel-Vos, W., Kremers, S., van Lenthe, F. J., \& Brug, J. (2007). Environmental correlates of physical activity in youth - a review and update. Obesity Reviews, 8(2), 129154.

44. Friedman, H., Martin, L., Tucker, J. M., Criqui, M., Kern, M., \& Reynolds, C. (2008). Stability of physical activity across the life-span. Journal of Health Psychology, 13(1), 966-978.

45. Golan, M., Weizman, A., Apter, A., \& Fainaru, M. (1998). Parents as the exclusive agents of change in the treatment of childhood obesity. American Journal of Clinical Nutrition, 67(1), 1130-1135.

46. Gregg, E. W., Pereira, M. A., \& Caspersen, C. J. (2000). Physical activity, falls, and fractures among older adults: a review of the epidemiologic evidence. Journal of the American Geriatrics Society, 48(8), 883-893.

47. Grissom, J. B. (2005). Physical fitness and academic achievement. Journal of Exercise Physiology Online, 8(1), 11-25.

48. Haerens, L., Cerin, E., Maes, L., Cardon, G., Deforche, B., \& De Bourdeaudhuij, I. (2008). Explaining the effect of a 1-year intervention promoting physical activity in middle schools: a mediation analysis. Public Health Nutrition, 11(5), 501-512. doi: 10.1017/S136898000700078X

49. Hamer, M., \& Chida, Y. (2009). Physical activity and risk of neurodegenerative disease: a systematic review of prospective evidence. Psychological Medicine, 39(1), 3.

50. Hamer, M., \& Stamatakis, E. (2009). Physical activity and mortality in men and women with diagnosed cardiovascular disease. European Journal of Cardiac Preventive Rehabilitation, 16(2), 156-160. doi: 10.1097/HJR.0b013e32831f1b77

51. Hardman, K. (2008). Physical education in schools: a global perspective. Kinesiology, 40(1), 5-28.

52. Hayman, L. L., Meininger, J. C., Daniels, S. R., McCrindle, B. W., Helden, L., Ross, J., . . . Metabolism. (2007). Primary prevention of cardiovascular disease in nursing practice: focus on children and youth: a scientific statement from the American Heart Association Committee on Atherosclerosis, Hypertension, and Obesity in Youth of the Council on Cardiovascular Disease in the Young, Council on Cardiovascular Nursing, Council on Epidemiology and Prevention, and Council on Nutrition, Physical Activity, and Metabolism.
Circulation, 116(3), 344-357. doi:

10.1161/CIRCULATIONAHA.107.184595

53. Herman, K. M., Craig, C. L., Gauvin, L., \& Katzmarzyk, P. T. (2009). Tracking of obesity and physical activity from childhood to adulthood: the Physical Activity Longitudinal Study. International Journal of Pediatric Obesity, 4(4), 281-288. doi: 10.3109/17477160802596171

54. Hillman, C. H., Buck, S. M., Themanson, J. R., Pontifex, M. B., \& Castelli, D. M. (2009). Aerobic fitness and cognitive development: Event-related brain potential and task performance indices of executive control in preadolescent children. Developmental Psychology; Developmental Psychology, 45(1), 114.

55. Hume, C., Salmon, J., \& Ball, K. (2005). Children's perceptions of their home and neighborhood environments, and their association with objectively measured physical activity: a qualitative and quantitative study. Health Education Research, 20(1), 1-13.

56. Hyndman, B., Telford, A., Finch, C., \& Benson, A. (2012). Moving Physical Activity Beyond the Schoo Classroom: A Social-ecological Insight for Teachers of the facilitators and barriers to students' noncurricular physical activity. Australian Journal of Teacher Education, 37(2), 1-24.

57. Jago, R., \& Baranowski, T. (2004). Non-curricular approaches for increasing physical activity in youth: a review. Preventive Medicine, 39(1), 157-163. doi: 10.1016/j.ypmed.2004.01.014

58. Jago, R., Wedderkopp, N., Kristensen, P., Moller, N., Andersen, L., Cooper, A., .. . Jago, R. (2008). Sixyear change in youth physical activity \& effect on fasting insulin \& HOMA. American Journal of Preventive Medicine, 35(6), 554-60.

59. Jakicic, J. M., \& Davis, K. K. (2011). Obesity and physical activity. Psychatric Clinics of North America, 34(4), 829-840. doi: 10.1016/j.psc.2011.08.009

60. Kannus, P., Haapasalo, H., Sankelo, M., Sievanen, H., Pasanen, M., Heinonen, A., . . . Vuori, I. (1995). Effect of starting age of physical activity on bone mass in the dominant arm of tennis and squash players. Annals of Internal Medicine, 123(1), 27-31.

61. Kannus, P., Haapasalo, H., Sievanen, H., Oja, P., \& Vuori, I. (1994). The site-specific effects of longterm unilateral activity on bone mineral density and content. Bone, 15(3), 279-284.

62. Kelty, S. F., Giles-Corti, B., \& Zubrick, S. R. (2008). Physical activity and young people: The impact of the built environment in encouraging play, fun and being active. Physical activity and children: new research. New York, Nova Science Publishers, Inc, 733.

63. Klein-Platat, C., Oujaa, M., Wagner, A., Haan, M., Arveiler, D., Schlienger, J., \& Simon, C. (2005). Physical activity is inversely related to waist circumference in 12-y-old French adolescence. International Journal of Obesity (Lond), 29(1), 9-14.

64. Knowler, W. C., Barrett-Connor, E., Fowler, S. E., Hamman, R. F., Lachin, J. M., Walker, E. A., . . . 
Diabetes Prevention Program Research, G. (2002).

Reduction in the incidence of type 2 diabetes with lifestyle intervention or metformin. New England Journal of Medicine, 346(6), 393-403. doi: 10.1056/NEJMoa012512

65. Krebs, N., Himes, J., Jacobson, D., Nicklas, T., Guilday, P., \& Styne, D. (2007). Assessment of Child and Adolescent Overweight and Obesity. Pediatrics, 120(4), 5193-5228.

66. Kriemler, S., Meyer, U., Martin, E., van Sluijs, E. M., Andersen, L. B., \& Martin, B. W. (2011). Effect of school-based interventions on physical activity and fitness in children and adolescents: a review of reviews and systematic update. British Journal of Sports Medicine, 45(11), 923-930. doi: 10.1136/bjsports-2011-090186

67. Krishnan, S., Rosenberg, L., \& Palmer, J. R. (2009). Physical activity and television watching in relation to risk of type 2 diabetes: the Black Women's Health Study. American Journal of Epidemiology, 169(4), 428-434. doi: 10.1093/aje/kwn344

68. Kumanyika, S., \& Parker, L. (2010). Committee on an Evidence Framework for Obesity Prevention Decision Making, Institute of Medicine, eds. Bridging the Evidence Gap in Obesity Prevention. A Framework to Inform Decision Making: Washington, DC: The National Academies Press.

69. Kumanyika, S. K. (2008). Environmental influences on childhood obesity: ethnic and cultural influences in context. Physiology \& behavior, 94(1), 61-70.

70. Lambourne, K., \& Donnelly, J. E. (2011). The role of physical activity in pediatric obesity. Psychiatric Clinics of North America, 58(6), 1481-1491, xi-xii. doi: 10.1016/j.pcl.2011.09.004

71. Lawman, H. G., Wilson, D. K., Van Horn, M. L., Resnicow, K., \& Kitzman-Ulrich, H. (2011). The relationship between psychosocial correlates and physical activity in underserved adolescent boys and girls in the ACT trial. Journal of Physical Health, 12(1), 116-129.

72. Lee, S. M., Burgeson, C. R., Fulton, J. E., \& Spain, C. G. (2007). Physical education and physical activity: results from the School Health Policies and Programs Study 2006. Journal of School Health, 77(8), 435-463.

73. Lindquist, C. H., Reynolds, K. D., \& Goran, M. I. (1999). Sociocultural determinants of physical activity among children. Preventive Medicine, 29(4), 305-312.

74. McCarthy, P. J., Jones, M. V., \& Clark-Carter, D. (2008). Understanding enjoyment in youth sport: A developmental perspective. Psychology of Sport \& Exercise, 9(1), 142-156.

75. Mclennan, J. (2004). Obesity in children: Tackling a growing problem. Australian Family Physician, 33(1), 33-36.

76. Metsios, G. S., Stavropoulos-Kalinoglou, A., Panoulas, V. F., Wilson, M., Nevill, A. M., Koutedakis, Y., \& Kitas, G. D. (2009). Association of physical inactivity with increased cardiovascular risk in patients with rheumatoid arthritis. European
Journal Cardiovascular Preventive Rehabilitation, 16(2), 188-194. doi: 10.1097/HJR.0b013e3283271ceb

77. Mitchell, N. S., Catenacci, V. A., Wyatt, H. R., \& Hill, J. O. (2011). Obesity: overview of an epidemic. Psychiatric Clinics of North America, 34(4), 717732. doi: 10.1016/j.psc.2011.08.005

78. Moore, J., Yin, Z., Duda, J., Gutin, B., \& Barbeau, P. (2009). Measuring enjoyment of physical activity in children: validation of the Physical Activity Enjoyment Scale. Journal of Applied Sport Psychology, 21(1), 116-129.

79. Mota, J., Ribeiro, J. C., \& Santos, M. P. (2009). Obese girls differences in neighbourhood perceptions, screen time and socioeconomic status according to level of physical activity. Health Education Research, 24(1), 98-104. doi: 10.1093/her/cyn001

80. Motl, R. W., Dishman, R. K., Saunders, R., Dowda, M., Felton, G., \& Pate, R. R. (2001). Measuring enjoyment of physical activity in adolescent girls. American Journal of Preventative Medicine, 21(2), 110-117.

81. Ntoumanis, N. (2002). Motivational clusters in a sample of British physical education classes. Psychology of Sports and Exercise, 3, 177-194.

82. Okely, A., Booth, M., \& Patterson, J. (2001). Relationship of physical activity to fundamental movement skills among adolescents. Medicine \& Science in Sports \& Exercise, 3, 1899-1904.

83. Oldridge, N. B. (2008). Economic burden of physical inactivity: healthcare costs associated with cardiovascular disease. European Journal of Cardiovascular Preventive Rehabilitation, 15(2), 130-139. doi: 10.1097/HJR.0b013e3282f19d42

84. Orozco-Beltran, D., \& Cos-Claramunt, F. X. (2008). Primary care diabetes in Spain. Primary Care Diabetes, 2(2), 101-103. doi: 10.1016/j.pcd.2008.03.001

85. Osorio, J. (2012). Obesity: physical activity reduces genetic contribution to obesity risk. Nature Reviews Endocrinology, 8(1), 2. doi: 10.1038/nrendo.2011.209

86. Pellegrini, A. D., \& Bohn, C. M. (2005). The role of recess in children's cognitive performance and school adjustment. Educational Research, 34(1), 13-19.

87. United States Department of Health and Human Services. (2004). Physical activity for children: A statement of guidelines for children ages 5-12 (2nd ed). Reston, VA: National Association for Sport and Physical Education (NASPE).

88. Physical Activity Guidelines for Americans. (2008). Retrieved from U.S. Department of Health \& Human Services:

http://www.health.gov/paguidelines/guidelines/defaul t.aspx

89. Pontifex, M. B., Raine, L. B., Johnson, C. R., Chaddock, L., Voss, M. W., Cohen, N. J., . . . Hillman, C. H. (2011). Cardiorespiratory fitness and the flexible modulation of cognitive control in 
preadolescent children. Journal of Cognitive Neuroscience, 23(6), 1332-1345.

90. Prochaska, J. O., \& Velicer, W. F. (1997). The transtheoretical model of health behavior change. American Journal of Health Promotion, 12(1), 38-48.

91. Reilly, J. J. (2007). Childhood obesity: An overview. Children \& society, 21(5), 390-396.

92. Ries, V., Voorhees, C., Gittelsohn, J., Roche, K., \& Astone, N. (2008). Adolescents' perceptions of environmental influences on physical activity. American Journal of Health Behavior, 32(1), 26-39.

93. Riley, A. (2004). Evidence that school-age children can self-report on their health. Ambulatory Pediatrics, 4(4), 374-376.

94. Rosenstock, I. M., Strecher, V. J., \& Becker, M. H. (1988). Social learning theory and the health belief model. Health Education \& Behavior, 15(2), 175183.

95. Rovniak, L. S., Anderson, E. S., Winett, R. A., \& Stephens, R. S. (2002). Social cognitive determinants of physical activity in young adults: a prospective structural equation analysis. Annals of Behavioral Medicine, 24, 149-156.

96. Ryan, R. M., \& Deci, E. L. (2000). Selfdetermination theory and the facilitation of intrinsic motivation, social development, and well-being. American Psychologist, 55(1), 68.

97. Saland, J. M. (2007). Update on the metabolic syndrome in children. Current Opinion in Pediatrics, 19(2), 183-191.

98. Sallis, J., \& Owen, N. (1999). Physical activity and behavioral medicine. Thousand Oaks, CA: Sage Publications.

99. Sallis, J. F., Prochaska, J. J., \& Taylor, W. C. (2000). A review of correlates of physical activity of children and adolescents. Medicine Science in Sports \& Exercise, 32(5), 963-975.

100.Salmon, J., Ball, K., Crawford, D., Booth, M., Telford, A., Hume, C., . . . Worsley, A. (2005). Reducing sedentary behaviour and increasing physical activity among 10-year-old children: overview and process evaluation of the 'Switch-Play' intervention. Health Promotion International, 20(1), 7-17. doi: 10.1093/heapro/dah502

101.Salmon, J., Brown, H., \& Hume, C. (2009). Effects of strategies to promote children's physical activity on potential mediators. International Journal of Obesity (Lond), 33 Suppl 1, S66-73.

102.Salmon, J., \& King, A. C. (2010). Population approaches to increasing physical activity and reducing sedentary behavior among children and adults. In D. Crawford, R. W. Jeffery, K. Ball \& J. Brug (Eds.), Obesity epidemiology: from aeitiology to public health (2nd ed.). New York, N.Y.: Oxford University Press.

103.Salmon, J., \& Okely, A. D. (2009). Physical activity in young people-assessment and methodological issues. Journal of Science \& Medicine in Sport, 12(5), 513-514.

104.Salmon, J., Timperio, A., Telford, A., Carver, A., \& Crawford, D. (2005). Association of family environment with children's television viewing and with low level of physical activity. Obesity Research, 13(11), 1939-1951.

105.Sawyer, M. G., Arney, F. M., Baghurst, P. A., Clark, J. J., Graetz, B. W., Kosky, R. J., . . Raphael, B. (2008). The mental health of young people in Australia: key findings from the child and adolescent component of the national survey of mental health and well-being. Australian \& New Zealand Journal of Psychiatry, 35(6), 806-814.

106.Scanlon, T. K., \& Lewthwaite, R. (1986). Social Psychological Aspects of Competition for Male Youth Sport Participants: IV. Predictors of Enjoyment. Journal of Sports Psychology, 8(1), 2535.

107.Serraglio, A. (2007). Victorian Population Health Survey Rural and Regional Health and Aged Care Services: Victorian Government Department of Human Services.

108.Spurrier, N. J., Magarey, A. A., Golley, r., Curnow, F., \& Sawyer, M. G. (2008). Relationships between the home environment and physical activity and dietary patterns of preschool children: a crosssectional study. International Journal of Behavioral Nutrition \& Physical Activity, 5(1), 31-43.

109.Stevenson, H. M., \& Burke, M. (1992). Bureaucratic logic in new social movement clothing: the limits of health promotion research. Canadian Journal of Public Health. Revue canadienne de sante publique, 83, S47.

110.Stokols, D. (1996). Translating social ecological theory into guidelines for community health promotion. American Journal of Preventive Medicine, 10(4), 282-298.

111.Suominen, H. (1993). Bone mineral density and long term exercise. An overview of cross-sectional athlete studies. Sports Medicine, 16(5), 316-330.

112.Taymoori, P., \& Lubans, D. R. (2008). Mediators of behavior change in two tailored physical activity interventions for adolescent girls. Psychology of Sport \& Exercise, 9(5), 605-619.

113.Telama, R. (2009). Tracking of Physical Activity from Childhood to Adulthood: A Review. Obesity Facts, 2(3), 187-195. doi: Doi 10.1159/000222244

114.Telford, A. (2010). Social-ecological models of physical activity. In R. Malpeli, A. Telford, R. Whittle \& M. Corrie (Eds.), Nelson Physical Education Units 3 \& 4: Nelson Cengage Learning.

115.Telford, A., Salmon, J., Timperio, A., \& Crawford, D. (2005). Quantifying and characterizing physical activity among 5- to 6- and 1- to 12-year-old childfren: the children's leisure activities study (CLASS). Pediatric Exercise Science, 17(1), 266280.

116.Timperio, A., Salmon, J., Ball, K., Baur, L. A., Telford, A., Jackson, M., . . . Crawford, D. (2008). Family physical activity and sedentary environments and weight change in children. International Journal of Pediatric Obesity, 3(3), 160-167.

117.Tolomio, S., Lalli, A., Travain, G., \& Zaccaria, M. (2009). [Effects of a combined weight-bearing and non-weight-bearing ( warm water) exercise program on bone mass and quality in postmenopausal women 
with low bone-mineral density]. Clinica Terapeutica, 160(2), 105-109.

118.Trost, S. (2005). Discussion paper for the development of recommendations for children's and youths' participation in health promoting physical activity (pp. 1-141). Commonwealth Department of Health and Ageing, Canberra.

119.Trost, S. G., \& Loprinzi, P. D. (2008). ExercisePromoting healthy lifestyles in children and adolescents. Journal of Clinical Lipidology, 2(3), 162-168.

120.Trost, S. G., Pate, R. R., Sallis, J. F., Freedson, P. S., Taylor, W. C., Dowda, M., \& Sirard, J. (2002). Age and gender differences in objectively measured physical activity in youth. Medicine \& Science in Sports \& Exercise, 34(2), 350-355.

121. Trudeau, F., Laurencelle, L., \& Shephard, R. J. (2004). Tracking of physical activity from childhood to adulthood. Medicine \& Science in Sports \& Exercise, 36(11), 1937-1943.

122. Van Der Horst, K., Paw, M. J., Twisk, J. W., \& Van Mechelen, W. (2007). A brief review on correlates of physical activity and sedentariness in youth. Medicine \& Science in Sports \& Exercise, 39(8), 1241-1250.

123. Veitch, J., Bagley, S., Ball, K., \& Salmon, J. (2006). Where do children usually play? A qualitative study of parents' perceptions of influences on children's active free-play. Health Place, 12(4), 383-393.

124. Veitch, J., Salmon, J., \& Ball, K. (2008). Children's active free play in local neighborhoods: a behavioral mapping study. Health Education Research, 23(5), 870-879.

125. Veitch, J., Salmon, J., \& Ball, K. (2010). Individual, social and physical environmental correlates of children's active free-play: a cross-sectional study.
International Journal of Behavioral Nutrition Physical Activity, 7, 11.

126. Virvidakis, K., Georgiou, E., Kortkotsidis, A., Ntalles, K., \& Proukakis, C. (199). Bone mineral content of junior competitive weight lifters. International Journal of Sports Medicine, 11(1), 244246.

127.Wheeler, B. W., Cooper, A. R., Page, A. S., \& Jago, R. (2010). Greenspace and children's physical activity: a GPS/GIS analysis of the PEACH project. Preventive Medicine, 51(2), 148-152.

128. World Health Organisation (WHO). (2003). Chronic disease information sheets: Physical Activity: World Health Organisation.

129. World Health Organisation (WHO). (2007). Move for health: Sedentary lifestyle: A global public health problem. Retrieved from: http://www.who.int/moveforhealth/advocacy/informa tion_sheets/sedentary/en/index.html

130.Williamson, D. F., Vinicor, F., Bowman, B. A., Centers For Disease, C., \& Prevention Primary Prevention Working, G. (2004). Primary prevention of type 2 diabetes mellitus by lifestyle intervention: implications for health policy. Annals of Internal Medicine, 140(11), 951-957.

131.United Kingdom Department of Health. (1998). Young and active? Young people and health enhancing physical activity- evidence and implications. In S. Biddle, J. Sallis \& N. Cavill (Eds.). London, England: Health Education Authority.

\section{$\triangle$ Brendon Hyndman}

International Graduate Centre of Education,

School of Education,

Charles Darwin University

Email: brendon.hyndman@cdu.edu.au 